\title{
Detection and Projection of Forest Changes by Using the Markov Chain Model and Cellular Automata
}

\author{
Griselda Vázquez-Quintero ${ }^{1}$, Raúl Solís-Moreno ${ }^{2}$, Marín Pompa-García ${ }^{2}$, \\ Federico Villarreal-Guerrero ${ }^{3}$, Carmelo Pinedo-Alvarez ${ }^{3}$ and Alfredo Pinedo-Alvarez ${ }^{3, *}$ \\ 1 Doctorado Institucional en Ciencias Agropecuarias y Forestales, Universidad Juárez del Estado de Durango, \\ Boulevard del Guadiana \#501, Ciudad Universitaria, Durango C.P. 34120, Mexico; griselda_vq@hotmail.com \\ 2 Facultad de Ciencias Forestales, Universidad Juárez del Estado de Durango, Boulevard Durango \#501, \\ Valle del Sur, Durango C.P. 34120, Mexico; rsolis@ujed.mx (R.S.-M.); mpgarcia@ujed.mx (M.P.-G.) \\ 3 Facultad de Zootecnia y Ecología, Universidad Autónoma de Chihuahua, Periférico Fco. R. Almada Km 1, \\ Chihuahua C.P. 31453, Mexico; fvillarreal@uach.mx (F.V.-G.); cpinedo@uach.mx (C.P.-A.) \\ * Correspondence: apinedo@uach.mx or apinedoa@gmail.com; Tel.: +52-614-434-0363 (ext. 15); \\ Fax: +52-614-434-0345
}

Academic Editor: Vincenzo Torretta

Received: 12 January 2016; Accepted: 26 February 2016; Published: 2 March 2016

\begin{abstract}
The spatio-temporal analysis of land use changes could provide basic information for managing the protection, conservation and production of forestlands, which promotes a sustainable resource use of temperate ecosystems. In this study we modeled and analyzed the spatial and temporal dynamics of land use of a temperate forests in the region of Pueblo Nuevo, Durango, Mexico. Data from the Landsat images Multispectral Scanner (MSS) 1973, Thematic Mapper (TM) 1990, and Operational Land Imager (OLI) 2014 were used. Supervised classification methods were then applied to generate the land use for these years. To validate the land use classifications on the images, the Kappa coefficient was used. The resulting Kappa coefficients were 91\%, 92\% and 90\% for 1973, 1990 and 2014, respectively. The analysis of the change dynamics was assessed with Markov Chains and Cellular Automata (CA), which are based on probabilistic modeling techniques. The Markov Chains and CA show constant changes in land use. The class most affected by these changes is the pine forest. Changes in the extent of temperate forest of the study area were further projected until 2028, indicating that the area of pine forest could be continuously reduced. The results of this study could provide quantitative information, which represents a base for assessing the sustainability in the management of these temperate forest ecosystems and for taking actions to mitigate their degradation.
\end{abstract}

Keywords: landsat; land use changes; simulation; temperate forest

\section{Introduction}

During the last decade, the decrement of forest areas has come to attention because of the great environmental impacts on the local, regional and global scales [1-3]. The population increase has resulted in high demand for goods and services; inducing changes on the land uses to meet global demands [4]. The forested areas of the planet cover large surfaces representing big carbon reservoirs. However, their reduction has significantly altered the natural landscape and is one of the factors contributing to the global climate change [5-8]. The forests of Mexico, which are also vulnerable to climate change [9], represent a carbon store of approximately eight billion tons [10], equivalent to the current global $\mathrm{CO}_{2}$ emissions. The carbon storage capability of these forests is rapidly being lost due to deforestation and degradation processes [11].

Temperate forests occupy the largest forest cover in Mexico, with about 32 million hectares, equivalent to the $18 \%$ of its territory. The highest partnerships diversity between pine and oak of the 
world occurs in this region [12]. However, each year, on average, 40 thousand hectares of temperate forest are lost. The deforestation alters biogeochemical cycles [13]. The expansion of agricultural lands, the illegal logging and the opening of pasturelands to feed cattle on forest areas has resulted in the fragmentation and degradation of the landscape [14]. The quantification of changes in the landscape is important for the understanding of the spatial and structural dynamics of land use and its associated ecological effects [15]. In this regard, it is important to understand the behavior of the areas occupied by forests and the relationships with the abiotic factors involved in their development, distribution and preservation [16]. To analyze the structure, function and dynamics of land use, it is necessary to link spatial patterns with the landscape to quantify the causes and consequences of its evolution [17].

Remote sensing data represent a source of rapid acquisition of land use information, with field supervision methods of low cost [18]. In this regard, the data from the Landsat satellite provides images since 1972, the year of its first mission. This satellite has a worldwide coverage with a medium spatial resolution [19]. Previous studies using information from remote sensing have been developed multitemporal and change detection techniques to monitor the forest dynamics [20-22]. Associated with the development of remote sensing, the techniques of land use classification have been refined through the years. One of the techniques commonly used is the maximum likelihood [23,24]. Other method of classification is object-oriented which takes groups of pixels as a unit of analysis. These pixels represent real objects on the ground instead of pixels isolated. The method of neural networks incorporates a multi-information model (spectral response, elevations, thematic maps) related to the statistical distribution of the data $[25,26]$. In relation to the above, each method offers some reliability in the classification of land use. The best method of classification depends on the interest of the user to discriminate specific categories [27].

Once a classification technique is applied, the comparison and analysis of satellite images from different dates is performed. The difference among the evaluated dates is assessed by map algebra [28-30]. Other techniques are based on multivariate analysis through regression of images [31]. The latter method is recently one of the most widely used to predict land use through the variation of this model [32]. However, the logistic regression models cannot quantify the change and serve to perform the temporal analysis [33]. In this regard, the use of Markov chains (MC) and cellular automata (CA), integrated to the spatio-temporal analysis represent an alternative to overcome these limitations. Markov chains and CA are stochastic models that incorporate the interaction effects of the spatial and temporal dynamics [34-36]. The Markov prediction methods can serve to analyze the dynamic behavior of land use in a time-space pattern to provide forecasts of future changes that can help in making decisions $[37,38]$. Some researchers who have applied traditional Markov models have shown their capabilities to describe the trends in the amount of change in land use [38-41]. Even though the Markov analysis itself can not simulate and predict changes in land use, the combined techniques between MC and CA offer the ability to analyze the spatiotemporal dynamics and also simulate future scenarios. However, Cellular Automata require factors in defining the simulation model of land use [39-41].

In this study, we analyzed and modeled the temporal dynamics of land use of a region of temperate forests in the town of Pueblo Nuevo, Durango, Mexico. The traditional Markov model and cellular automata techniques were used to forecast future changes of land use in the study area.

\section{Materials and Methods}

\subsection{Study Area}

The study area is located in the southern region of the State of Durango, in the municipality of Pueblo Nuevo, with a surface area of 138,710 ha (Figure 1). The vegetation of this region corresponds to a temperate forest. The most abundant forest species are: Quercus sideroxyla Humb. and Bonpl., Q. durifolia V. Seem, Pinus cooperi Ornelasi, P. engelmannii Carr., P. durangensis Schl., P. leiophylla Schl. and Cham., P. teocote Schlech and Cham., and Hardwood species such as Arbutus madrensis and A. tesselata. 
The herbaceous community is represented by: Bouteloua spp. and Arcthosthaphilos pungens HBK present in open areas with some disturbance.

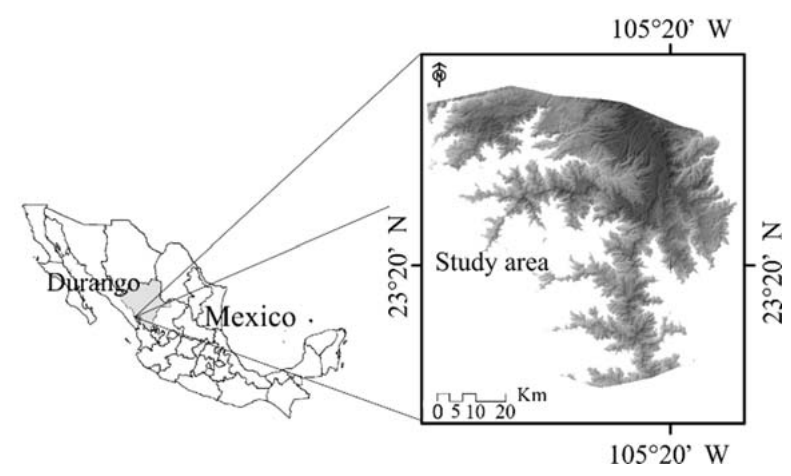

Figure 1. Location of the study area, municipality of Pueblo Nuevo, Durango.

The climate of the region is temperate humid with summer rains. The air temperature oscillates in the range of $8-26^{\circ} \mathrm{C}$ and the precipitation ranges from 800 to $2000 \mathrm{~mm}$. The most abundant soil types are: Leptosol, luvisol, regosol, umbrisol, cambisol, phaeozem and fluvisol [42]. These conditions favor the growth of pine and oak communities, which are the most dominant in the study area.

\subsection{Data Collection}

Landsat image data were used; the first one from the sensor Landsat Multispectral Scanner (MSS), capture date: 4 April 1973; the second from the Landsat Thematic Mapper (TM), capture date: 26 March 1990 and the third one from the Landsat 8 (Operational Land Imager, OLI), capture date: 6 May 2014. The information was acquired from the US Geological Survey (USGS). The data from the Landsat MSS has four spectral bands, with a spatial resolution of $60 \mathrm{~m}$; however, it was re-sampled to $30 \mathrm{~m}$. The TM sensor has seven spectral bands and its spatial resolution is $30 \mathrm{~m}$. Data from the Landsat 8 has nine spectral bands with a spatial resolution of $30 \mathrm{~m}$ in bands $1-7$ and 9, while its eighth band (panchromatic) has a spatial resolution of $15 \mathrm{~m}$. The bands from the evaluated sensors are located in the wavelengths of the optical and infrared regions of the electromagnetic spectrum. To make a coherent superposition of the classified images, the final resolution utilized for all of them was $30 \mathrm{~m}$. This was necessary for later analysis carried out with CA.

\subsection{Data Pre-Processing}

The satellite images from 1973, 1990 and 2014 were radiometrically corrected. The conversion from digital numbers (DN's) to reflectance values was performed with the process called top of the atmosphere (TOA). This process is necessary to make comparisons among the images from different dates. The radiometric conversion for the Landsat MSS and TM sensors was performed by following the Equations (1) and (2), where the spectral radiance $\left(L_{\lambda}\right)$ and the TOA reflectance $\left(\rho_{\lambda}\right)$ were obtained:

$$
\begin{gathered}
L_{\lambda}=\left(\left(\operatorname{Lmax}_{\lambda}-\operatorname{Lmin}_{\lambda}\right) /(Q C A \operatorname{Lmax}-Q C A L \min )\right) \times(Q C A L-Q C A L \min )+\operatorname{Lmin}_{\lambda} \\
\rho_{\lambda}=\frac{\pi \times L_{\lambda} \times d^{2}}{E S U N_{\lambda} \times \cos \theta_{s}}
\end{gathered}
$$

where $Q C A L$ is $\mathrm{DN}, \operatorname{Lmin}_{\lambda}$ is the spectral radiance scales to $Q C A L \min , \operatorname{Lmax}_{\lambda}$ is the spectral radiance scales to QCALmax, QCALmin is the minimum quantized calibrated pixel value, QCALmax is the máximum quantized calibrated pixel value, $d$ is the distance from the earth to the sun, $E S U N_{\lambda}$ is the mean solar exoatmospheric irradiance, and $\theta_{s}$ is the solar zenith angle. 
In the case of the data from the Landsat 8 , the radiometric conversion was performed by applying the Equation (3).

$$
\rho_{\lambda}^{*}=\frac{\rho^{\lambda}}{\sin \theta_{S E}}
$$

where $\rho^{\lambda}$ is the TOA planetary reflactance, with correction for solar angle, and $\theta_{S E}$ is the local sun elevation angle.

For reflectance normalization of the images from 1973 and 1990 the image from Landsat 8 was used. This process allows to making a modification on the histograms by improving the brightness values in the images from 1973 and 1990, taking as a reference the image from 2014. This process allows to minimizing the spectral variations of the land use covers [43].

\subsection{Image Classification}

For the supervised classification, the method of maximum likelihood was used. This method uses training areas as polygons and decision rules of maximum likelihood (Equation (4)) to classify images. Three classified land use maps derived from the Landsat MSS 1973, the Landsat TM 1990 and the Landsat sensor OLI 2014 were obtained; one from each sensor. The three classified images were adjusted to the same spatial resolution of $30 \mathrm{~m}$. Given that the vegetation of the study area predominantly consisted of natural temperate forests, distributed in a scarp topography, the water harvesting takes place mainly through infiltration and runoff processes towards lower places in the watershed. Then, the accumulation of water or the presence of water bodies in the zone was practically null. Therefore, based on the dominance of forest species and their ecological and economical importance in the region, the land uses classified in all the images were: Open Areas (Oa), Oak forests (Of) and Pine forests (Pf).

$$
g i(x)=\operatorname{In} p(\omega i)-\frac{1}{2} \operatorname{In}\left|\sum i\right|-\frac{1}{2}\left(x-m_{i}\right)^{T} \sum i^{-1}\left(x-m_{i}\right)
$$

where: $g i=$ class, $x=n$-dimensional data (where $n$ is the number of bands), $p\left(\omega_{i}\right)=$ probability that class $\omega_{i}$ appears in the image and that is assumed for all classes, $\left|\sum_{i}\right|=$ determinant of co-variance matrix data from class $\omega_{i}$, and $\sum_{i}^{-1}=$ inverse matrix, $m_{i}=$ vector.

\subsection{Spectral Separability}

The canopy structure of the plants belonging to each land use played an important role during the discrimination process. The canopy reflectance in the infrared range (SWIR) is closely related to the water absorption. Meanwhile, the energy dispersion is also caused by the canopy structure and by the aerial space among the leaves $[44,45]$. The spectral separability was determined by the Jeffrey-Matusita distance (JM) [46], according to Equation (5). This method includes the value of the Bathacharyya distance (Equation (6)) [47].

$$
\begin{gathered}
J M=2\left(1-e^{-B}\right) \\
B=\frac{1}{8}\left(m_{1}-m_{2}\right)^{2} \frac{2}{\sigma_{1}^{2}+\sigma_{1}^{2}}+\frac{1}{2} \operatorname{In} \frac{\sigma_{1}^{2} \sigma_{1}^{2}}{2 \sigma_{1}^{2} \sigma_{1}^{2}}
\end{gathered}
$$

where $B$ is the Bhattacharyya distance, $m_{1}, m_{2}$ and $\sigma 1, \sigma 2$ are the class means and variances, respectively. The $J M$ distance has values from 0 to 2 . A value of 2 indicates a complete separability between two classes and lower values indicate misclassified classes.

\subsection{Classification Accuracy}

The Kappa coefficient was used to validate the classifications (Equation 7) by employing 300 control points for each year, taken from the compositions of false color images. The Kappa coefficient and the error matrix are considered as common techniques in measuring the accuracy of 
thematic maps generated by the classification process [48]. Measurements of particular categories of classification can be verified with field data or reference data [49].

$$
K_{A P P A}=\frac{N \sum^{K} X_{i i} \sum^{k}\left(X_{i+} \times X_{+i}\right)}{N^{2}-\sum^{k}\left(X_{i+} \times X_{+i}\right)}
$$

where: $K_{A P P A}=$ Kappa index, $k=$ number of matrix files, $X i i=$ observation number on row $i$ and column $I$ (along the diagonal), $X_{i+}$ and $X_{+i}=$ total marginal for row $i$ and column $i$, respectively, $N=$ total number of observations.

\subsection{Land Use and Land Cover Change Using Markov Chain}

The simulation technique used to predict the change in land use was the Markov Chains. The Markov Chains is a stochastic process model that describes the probability of change from one state to another, i.e., from one land use type to another, using a transition probability matrix [34-36]. The transition probability would be the probability that a land cover type (pixels) at the time $t_{0}$ changes to another land cover type in the time $t_{1}$. Therefore, changes in land use between the dates were used to develop a probability transition matrix and then predict land uses for a future time. This matrix is the result of the crossing between the images by setting a proportional error. The transition probability maps are elaborated from the three land uses generated through the process of classification and these are used to calculate projections of possible changes between the specified times. The mathematical expression of the transition probability is:

$$
\begin{gathered}
\sum_{I=1}^{m} P i j=1 i=1,2 \ldots \ldots m \\
P=(P i j)=\begin{array}{ccc}
P 11 & P 12 \ldots & P 1 m \\
P 21 & P 12 & P 2 m \\
P m 1 & P n 2 & P m m
\end{array}
\end{gathered}
$$

where: $P i j=$ the probability of transition from one land use to a another, $\mathrm{m}=$ the type of land use of the area studied, $P i j$ values are within the range $0-1$.

The combination of Markov and Cellular Automata (CA_Markov) allows simulating the evolution of the geographical area represented by pixels. Each pixel can take a value from a finite set of states. All pixels are affected by a transition function that takes as arguments the measured values and values of the neighboring pixels as a function of time. For the study area, the transition function was determined based on the difference between 1990 and 2014. CA_Markov then used this transition function to predict the land cover for 2028. In other words, the transition probability matrix, created from the changes observed between 1990 and 2014, the transition probability maps of 2014 and each scenario were used to produce maps of land use for the year 2028. In an iterative process CA_Markov uses the transition probability maps of each land cover to establish the inherent suitability of each pixel to change from one land use type to another. To assign a weight of suitability to the pixels that are away from the pixel analyzed, a $5 \times 5$ filter (Figure 2) was used [50]. Since the probability of changes during the years analyzed stays constant, any year after 2014 can be projected. However, projections in the short term are more realistic than projections in the long term, so we run the simulation until 2028. 


\begin{tabular}{|l|l|l|l|l|}
\hline 0 & 0 & 1 & 0 & 0 \\
\hline 0 & 1 & 1 & 1 & 0 \\
\hline 1 & 1 & 1 & 1 & 1 \\
\hline 0 & 1 & 1 & 1 & 0 \\
\hline 0 & 0 & 1 & 0 & 0 \\
\hline
\end{tabular}

Figure 2. $5 \times 5$ filter configuration used in CA Markov.

\subsection{Validation of the Model}

The validation of the prediction model of land use change was carried out by using the simulation result of land use from Markov for 2014. This, with the reference map obtained from the supervised classification process of the same year. Through the comparison of the observed and simulated values, the model was validated. A transition matrix was generated to analyze the probability of change in land use.

\subsection{Cellular Automata (CA)}

Cellular Automata is a simulation model where the space and time are discrete variables and interactions assigned are local variables [51]. Cellular automata analysis was carried out by the module of CA_Markov in the software Idrisi Selva. This module uses the output of the analysis of the Markov Chain and predicts the land use for a future time. To predict the land use, the supervised classifications for the three periods were used.

\section{Results and Discussion}

\subsection{Spectral Serability}

Table 1 shows the results of the $J M$ distance for the land uses analyzed in this study corresponding to the years 1973, 1990 and 2014. According to the bands processed from the Landsat sensors analyzed, it can be observed that the fifth band of the sensors TM and OLI8 show the highest values of spectral separability for the clases OA vs. Of, OA vs. Pf and Of vs. Pf $(J M=1.48,1.65,1.67)$. The analysis also shows that the infrared band (band 4 in Landsat MSS; band 4 in Landsat TM; band 5 in Landsat OLI8) plays a key role in the discrimination of the land uses studied.

Table 1. JM distance for the land uses of Oa vs. Of, Oa vs. Pf and Of vs. Pf.

\begin{tabular}{ccccccc}
\hline Landsat MSS & Landsat TM & Landsat OLI8 & Band Name & Oa vs. Of & OA vs. Pf & Of $v$ s. Pf \\
\hline 1 & 1 & 2 & Blue & 1.33 & 1.39 & 0.88 \\
2 & 2 & 3 & Green & 1.23 & 1.40 & 0.97 \\
3 & 3 & 4 & Red & 1.11 & 1.38 & 1.13 \\
4 & 4 & 5 & NIR & 1.45 & 1.46 & 1.65 \\
& 5 & 6 & SWIR1 & 1.48 & 1.65 & 1.67 \\
& 7 & 7 & SWIR2 & 1.47 & 1.48 & 1.52 \\
\hline
\end{tabular}

\subsection{Land Use Classification 1973, 1990 and 2014}

Three types of land use were determined for the study area, as they were the most representative of the region (Figure 3). The land use of OA was the one presenting the least spatial distribution in the study area. Grassland areas, populated areas and scrubland areas represented this class. According to the natural potential of the region, these areas were not significant in terms of their spatial extent, followed by the class Of and the class Pf. The land use classification of 2014 was the one presenting the largest errors. The estimated global precision, based on the error matrix, was $92 \%$ with a kappa 
index of 0.90 . In this year, the lowest precision was presented by the class of OA, both for the producer precision (92\%) and the user precision (91\%). The land use classification for the year 1990 showed the highest precision, showing less errors in the spectral characterization of classes, and registering a global precision of $94 \%$ with a kappa index of 0.92 . For the year 1973 the global precision was $93 \%$ with a kappa index of 0.91 (Table 2). The final global precision reached for the maps was due mainly to the individual precision obtained for each of the three classes. All of them presented producer precisions within the range of $91 \%-96 \%$ and user precisions within the range of $91 \%-95 \%$.
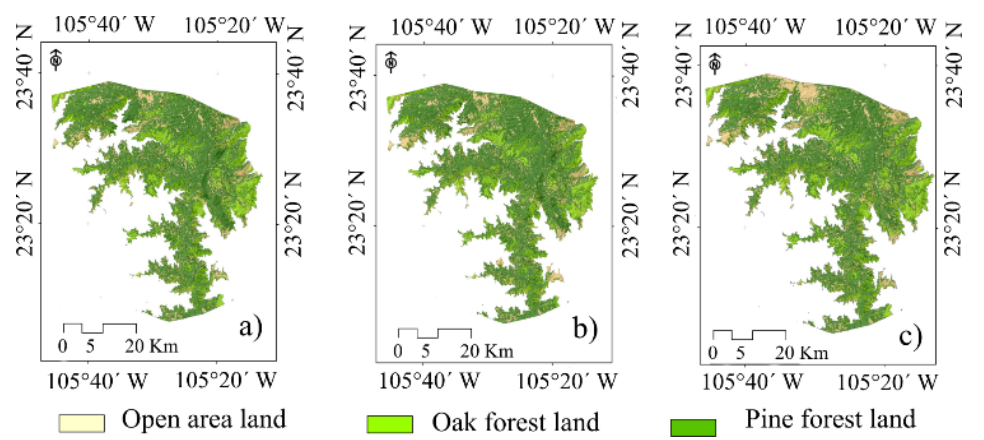

Figure 3. Land use/land cover maps for the years (a) 1973; (b) 1990 and (c) 2014.

Table 2. Accuracy assessment of the classified land use maps.

\begin{tabular}{ccccc}
\hline \multirow{2}{*}{ Years/Classes } & \multicolumn{4}{c}{ Classification Accuracy } \\
\cline { 2 - 5 } & $\begin{array}{c}\text { Producer's Accuracy } \\
\mathbf{( \% )}\end{array}$ & $\begin{array}{c}\text { User's Accuracy } \\
\mathbf{( \% )}\end{array}$ & $\begin{array}{c}\text { Overall Accuracy } \\
\mathbf{( \% )}\end{array}$ & Cohen's Kappa \\
\hline 1973 & & & 93 & 0.91 \\
Open areas & 93 & 91 & & \\
Oak forest & 94 & 94 & 0.92 \\
Pine forest & 93 & 93 & & \\
\hline 1990 & & & & \\
Open areas & 93 & 92 & \\
Oak forest & 92 & 91 & \\
Pine forest & 96 & 92 & \\
\hline 2014 & & & \\
Open areas & 91 & 91 & \\
Oak forest & 93 & 95 & \\
Pine forest & 94 & 94 & \\
\hline
\end{tabular}

\subsection{Land Use and Land Cover Change (1973-2014)}

Once the land uses were obtained through the method of supervised classification, we analyzed the land use change dynamics. Table 3 shows the surface change dynamics in each class. From 1973 to 1990 the class of OA increased by 1437 ha, the class of Of lose 908 ha and the class of Pf lose 528 ha. The increase of the class occurred at the expense of the classes of Of and Pf. However, the most important change dynamics occurred during the last 24 years of the period analyzed (1990-2014). The class of Pf showed the biggest loss with 4600 ha. During this period the classes of Of and OA increased by 1928 ha and 2621 ha, respectively (Figure 4). 
Table 3. Areas (ha), percentages and changes of land use for the years 1973, 1990 and 2014.

\begin{tabular}{|c|c|c|c|c|c|c|c|c|}
\hline \multirow{3}{*}{ Land Use } & \multicolumn{6}{|c|}{ Area (in ha) and Percentages (\%) } & \multicolumn{2}{|c|}{ Changes (in ha) } \\
\hline & \multicolumn{2}{|c|}{1973} & \multicolumn{2}{|c|}{1990} & \multicolumn{2}{|c|}{2014} & \multirow{2}{*}{ 1973-1990 } & \multirow{2}{*}{ 1990-2014 } \\
\hline & Area & $\%$ & Area & $\%$ & Area & $\%$ & & \\
\hline Open areas land & $18,304.57$ & 13.20 & $19,742.13$ & 14.23 & $22,363.47$ & 16.12 & -1437.56 & -2621.34 \\
\hline Oak Forest land & $29,327.24$ & 21.14 & $28,418.46$ & 20.49 & $30,397.13$ & 21.91 & 908.78 & -1978.67 \\
\hline Pine Forest land & $91,078.73$ & 65.66 & $90,549.94$ & 65.28 & $85,949.94$ & 61.96 & 528.79 & 4600 \\
\hline
\end{tabular}

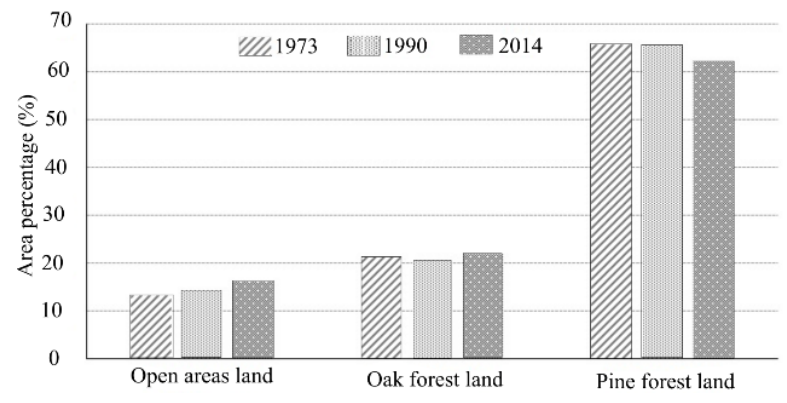

Figure 4. Percentage of area occupied by each land use in 1973, 1990 and 2014.

The temporal land use changes during the period analyzed (1973-2014) are shown in Figure 5. The land use change in the region resulted in a steady loss of Pf, represented by a decrement of 5128.79 ha. In contrast, the classes of OA and Of increased by 4059 ha and 1070 ha, respectively. These changes could be attributed to the wood harvesting that takes place in the region. This activity is perhaps one of the main factors that impact the sustainability of the temperate forests of the region and threatens the communities living in such forest [52-54].
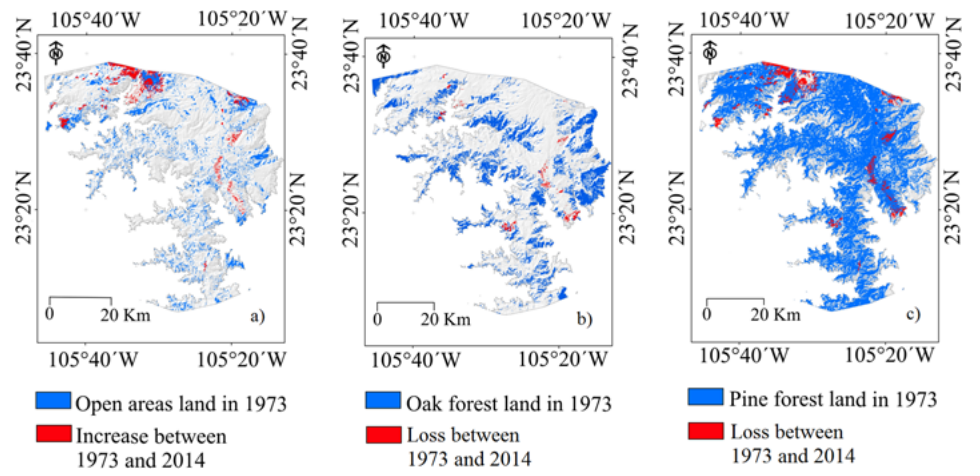

Figure 5. Changes in Land uses between 1973 and 2014: (a) Open areas; (b) Oak forest and (c) Pine forest.

\subsection{Validation of Land use Change Projection}

For the model validation, we compared the simulated land use areas by Markov Chains with the actual ones. The results are shown in Table 4, in which three land use types presented relative errors lower than $4 \%$. The best agreement was shown by the pine forest type, where the actual area is $85,949.9$ ha, while the corresponding simulated area is 85,732.41 ha. Thus, the developed Markov model is verified to effectively predict area change of land use in the future. Meanwhile, the Markov-Cellular Automata's overall simulation success was $96.12 \%$ in 2014 . In addition, the kappa coefficient was determined to be 0.92 , also showing a high precision. Therefore, the Markov-CA model can be used to forecast the spatial distribution of land use in the future. 
Table 4. Comparison of land use in 2014 generated by supervised classification processes against predicted by Markov techniques and CA.

\begin{tabular}{ccccc}
\hline \multirow{2}{*}{ Land Use } & \multicolumn{2}{c}{ Observed 14 } & \multicolumn{2}{c}{ Predictor 14 } \\
\cline { 2 - 5 } & Area (ha) & Total Area (\%) & Area (ha) & Total Area (\%) \\
\hline Open areas & $22,363.44$ & 16 & $21,988.89$ & 16 \\
Oak forest & $30,397.13$ & 22 & $30,989.21$ & 22 \\
Pine forest & $85,949.94$ & 62 & $85,732.41$ & 62 \\
\hline
\end{tabular}

\subsection{Land Use Change Projection}

The land use was projected using Markov's transition probability matrices (Table 5). A transition matrix summarizes the dynamics of each land use. The results show how the class of OA expanded at the expense of the classes of Pf and Of. The most significant changes occurred during the period 1990-2014, where the class of Pf had the highest loss with 4600 ha. The probability of change in this category was $42 \%$, compared to $54 \%$ for the period 1973-1990. In the last period studied, the classes of OA and Of increased its surface area in 2621 and 1978 ha, respectively. The transition matrix showed values from $25 \%$ to $30 \%$ for this same period, whereas for the period of 1973-1990 the values were 18\% and $27 \%$. The loss of Pf area during the evaluated period reveals some level of degradation of these ecosystems, which reduces the environmental sustainability of these forests. The changes were mainly caused by wood harvesting, as well as construction of roads and power lines [55-57].

Table 5. Transition probability matrices of land use changes for three periods (\%).

\begin{tabular}{cccc}
\hline & Pine Forest & Oak Forest & Open Areas \\
\hline 1973-1990 & & & \\
\hline Pine forest & 0.543 & 0.167 & 0.289 \\
Oak forest & 0.187 & 0.315 & 0.498 \\
Open areas & 0.276 & 0.204 & 0.519 \\
\hline 1990-2014 & & & \\
\hline Pine forest & 0.422 & 0.208 & 0.369 \\
Oak forest & 0.308 & 0.294 & 0.398 \\
Open areas & 0.255 & 0.289 & 0.456 \\
\hline 2014-2028 & & & \\
\hline Pine forest & 0.379 & 0.229 & 0.392 \\
Oak forest & 0.399 & 0.246 & 0.354 \\
Open areas & 0.252 & 0.294 & 0.453 \\
\hline
\end{tabular}

The land use projection for the year 2028 was based on the transition probability matrices. Figure 6 shows the spatial distribution of the land use classes for 2028. According to the transition matrix presented in Table 4, the class of OA will continue to increase its area in $25 \%$ while the classes of Pf and Of will decrease their surface in $37 \%$ and $39 \%$, respectively. These changes will be induced by the anthropogenic activities that take place in the area. The Global Partnership on Forest Landscape Restoration reports that more than 2000 million hectares of forestland were completely cleared worldwide over the past centuries. These areas are in a state of degradation [58]. 

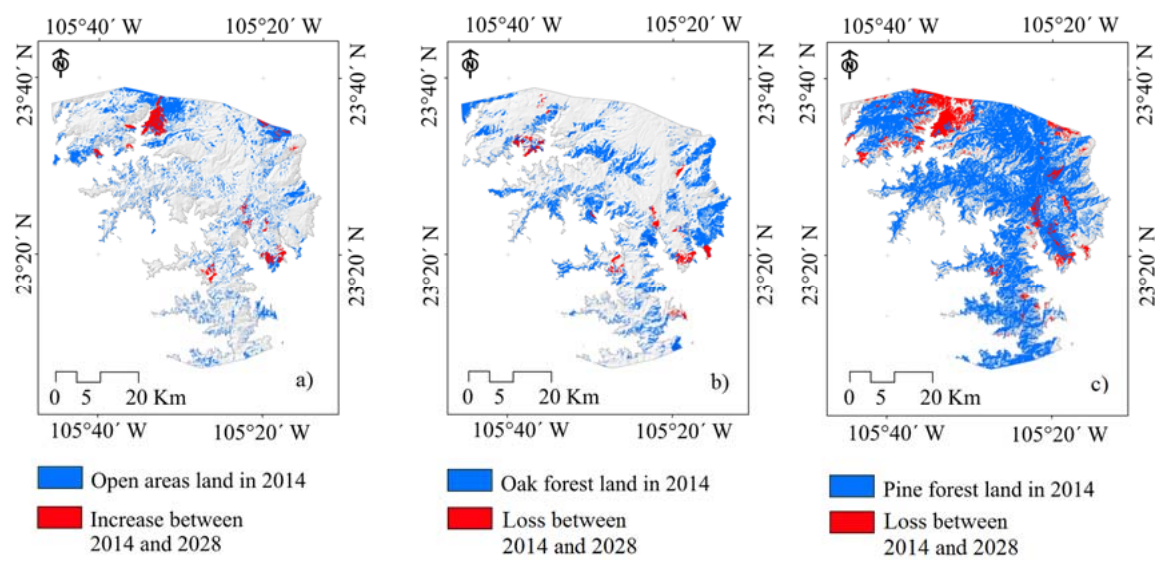

Figure 6. Simulation of land use changes during 2014-2028: (a) Open areas; (b) Oak forest; (c) Pine forest.

\section{Conclusions}

The simulation of the spatio-temporal dynamics of temperate forests represent an alternative for the mapping of forest ecosystems in a given time series. The classification of satellite images showed a good level of accuracy with respect to ground reference data, as supported for the values of the Kappa coefficient. In the period of 1973-2014 the class of Pf lost more than five thousand hectares. This land was converted to other land uses. The principal causes contributing to this decline were manly forestry, construction of roads and power lines. The analysis of the trends in land use change by using Markov Chains and CA shows the influence of these activities in the region. The land uses of the temperate forests projected for 2028 show a similar trend when compared to the period 1973-2014, where 4800 ha of pines will be probably lost. The open areas will increase to $4200 \mathrm{ha}$, and the oak forest will increase by 1400 ha. It is important that the government institutions involved with the forest management policies take action in the conservation, protection and production of the temperate forest ecosystems. Overall, the combined methods in this study demonstrate the usefulness in applying remote sensing to monitor spatial and temporal changes of temperate forests. The results of this study could provide quantitative information, which represents a base for assessing the sustainability in the management of these temperate forest ecosystems.

Acknowledgments: We deeply thank the Consejo Nacional de Ciencia y Tecnología (CONACYT-Mexico) for supporting the graduate studies of the first author of this manuscript. We also thank Jesus A. Prieto-Amparán, graduate student of the Universidad Autónoma de Chihuahua, for his valuable assistance on the analysis of the data.

Author Contributions: Alfredo Pinedo and Griselda Vázquez conceived and designed the research; Alfredo Pinedo, Federico Villarreal and Griselda Vázquez processed the data and elaborated the first draft; Raúl Solís, Marin Pompa, Carmelo Pinedo, Alfredo Pinedo and Griselda Vázquez analyzed the data. All authors have read and approved the final manuscript.

Conflicts of Interest: The authors declare no conflict of interest.

\section{References}

1. Cabrera, V.A.; Vilalta, M.J. Patterns of forest decline and regeneration across scots pine populations. Ecosystems 2013, 16, 323-335. [CrossRef]

2. Chen, F.C.; Son, T.N.; Chang, B.N.; Chen, R.C.; Chang, Y.L.; Valdez, M.; Centeno, G.; Thompson, A.C.; Aceituno, L.J. Multi-decadal mangrove forest change detection and prediction in Honduras, Central America, with Landsat imagery and a Markov chain model. Remote Sens. 2013, 5, 6408-6426. [CrossRef]

3. Lambin, F.E.; Meyfroidt, P. Global land use change, economic globalization, and the looming land scarcity. PNAS 2011, 108, 3465-3472. [CrossRef] [PubMed] 
4. Yu, X.J.; Ng, C.N. Spatial and temporal dynamics of urban sprawl along two urban-rural transects A case study of Guangzhou, China. Landsc. Urban Plan. 2007, 79, 96-109. [CrossRef]

5. Leuzinger, S.; Luo, Y.; Beier, C.; Dieleman, W.; Vicca, S.; Körner, C. Do global change experiments overestimate impacts on terrestrial ecosystems? Trends Ecol. Evol. 2011, 26, 236-241. [CrossRef] [PubMed]

6. Watson, R.T.; Noble, I.R.; Bolin, B.; Ravindranath, N.H.; Verardo, D.J.; Dokken, D.J. Land Use, Land-Use Change and Forestry: A Special Report of the Intergovernmental Panel on Climate Change, 1st ed.; Cambridge University Press: Cambridge, UK, 2000; p. 388.

7. Abdalla, M.; Saunders, M.; Hastings, A.; Williams, M.; Smith, P.; Osborne, B.; Lanigan, G.; Jones, M.B. Simulating the impacts of land use in Northwest Europe on Net Ecosystem Exchange (NEE): The role of arable ecosystems, grasslands and forest plantations in climate change mitigation. Sci. Total Environ. 2013, 465, 325-336. [CrossRef] [PubMed]

8. Dale, V.H. The relationship between land-use change and climate change. Ecol. Appl. 1997, 7, 753-769. [CrossRef]

9. Villers, R.L.; Trejo, V. Assessment of the vulnerability of forest ecosystem to climate change in Mexico. Clim. Res. 1997, 9, 87-93. [CrossRef]

10. Mansera, O.; Ordóñez, M.J.; Dirzo, R. Carbon emissions from Mexican forests: Current situation and long-term scenarios. Clim. Change 1997, 35, 265-295. [CrossRef]

11. Grimm, N.B.; Grove, J.M.; Pickett, S.T.A.; Redman, C.L. Integrated approaches to long-term studies of urban ecological systems. Bioscience 2000, 50, 571-584. [CrossRef]

12. González, E.M.S.; González, E.M.; Tena, F.A.; González, R.L.; López, E.L. Vegetación de la sierra madre occidental, México: Una síntesis. Acta Bot. Mex. 2012, 100, 351-403.

13. Potter, S.C. Terrestrial biomass and the effects of deforestation on the global carbon cycle results from a model of primary production using satellite observation. Bioscience 1999, 49, 769-778. [CrossRef]

14. Manjarrez-Domínguez, C.; Pinedo-Alvarez, A.; Pinedo-Alvarez, C.; Villarreal-Guerrero, F.; Cortes-Palacios, L. Vegetation landscape analysis due to land use changes on arid lands. Pol. J. Ecol. 2015, 63, 272-279. [CrossRef]

15. Turner, M. Landscape ecology in North America: Past, present and future. Ecology 2005, 86, 1967-1974. [CrossRef]

16. Bormann, F.H.; Likens, G.E. Pattern and Process in a Forested Ecosystem, 1st ed.; Springer-Verlag: New York, NY, USA, 1994; p. 245.

17. Kabba, S.T.V.; Li, J. Analysis of land use and land cover changes, and their ecological implications in Wuhan, China. J. Geogr. Geol. 2011, 3, 104-118. [CrossRef]

18. Pal, M.; Mather, P.M. Assessment of the effectiveness of support vector machines for hyperspectral data. Future Gener. Comput. Syst. 2004, 20, 1215-1225. [CrossRef]

19. Hansen, M.C.; Loveland, T.R. A review of large are monitoring of land cover change using Landsat data. Remote Sens. Environ. 2012, 122, 66-74. [CrossRef]

20. Tang, J.; Wang, L.; Zhang, S. Investigating landscape pattern and its dynamics in Daqing, China. Int. J. Remote Sens. 2005, 26, 2259-2280. [CrossRef]

21. Read, J.M.; Lam, N.S. Spatial methods for characterizing land cover and detecting land-cover changes for the tropics. Int. J. Remote Sens. 2002, 23, 2457-2474. [CrossRef]

22. Coppin, P.; Jonckheere, I.; Nackaerts, K.; Muys, B.; Lambin, E. Digital change detection methods in ecosystem monitoring: A review. Int. J. Remote Sens. 2004, 25, 1565-1596. [CrossRef]

23. Bolstad, P.; Lillesand, T.M. Rapid maximum likelihood classification. Photogramm. Eng. Remote Sens. 1991, $57,67-74$.

24. Franklin, J.; Woodcock, C.E.; Warbington, R. Multi-attribute vegetation maps of forest services lands in California supporting resource management decisions. Photogramm. Eng. Remote. Sens. 2000, 66, 1209-1217.

25. Mas, J.F.; Flores, J.J. The application of artificial neural networks to the analysis of remotely sensed data. Int. J. Remote Sens. 2008, 29, 617-663. [CrossRef]

26. Lin, Y.P.; Chu, H.J.; Wu, C.F.; Verburg, P.H. Predictive ability of logistic regression, auto-logistic regression and neural network models in empirical land-use change modeling-A case study. Int. J. Geogr. Inf. Sci. 2011, 25, 65-87. [CrossRef]

27. Brown, D.G.; Page, S.; Riolo, R.; Zellner, M.; Rand, W. Path dependence and the validation of agent-based spatial models of land use. Int. J. Geogr. Inf. Sci. 2005, 19, 153-174. 
28. Dewan, A.M.; Yamaguchi, Y.; Rahman, M.Z. Dynamics of land use/cover changes and the analysis of landscape fragmentation in Dhaka Metropolitan, Bangladesh. GeoJournal 2012, 77, 315-330. [CrossRef]

29. Guild, L.; Cohen, W.; Kauffman, J. Detection of deforestation and land conversion in Bondonia, Brazil using change detection techniques. Int. J. Remote Sens. 2004, 25, 731-750. [CrossRef]

30. Pinedo, A.C.; Pinedo, A.A.; Martinez, Q.R.M. Analysis of deforested areas in the north central region of the Sierra Madre Occidental, Chihuahua, México. Tecnociencia Chihuahua 2007, 1, 36-43.

31. Yuan, D.; Elvidge, C. NALC land cover change detection pilot study: Washington DC data experiments. Remote Sens. Environ. 1998, 66, 166-178. [CrossRef]

32. Verhagen, P. Case Studies in Archaeological Predictive Modeling; Amsterdam University Press: Amsterdam, The Netherlands, 2007; p. 224.

33. Lambin, E.F. Modelling Deforestation Processes: A Review; Office for Official Publications of the European Community: Brussels, Belgium, 1994.

34. Glenn, D.C.; Lewin, R.K.; Peet, T.T.V. Plant Succession: Theory and Prediction; Chapman \& Hall: London, UK, 1992.

35. Hu, Z.; Lo, C. Modeling urban growth in Atlanta using logistic regression. Comput. Environ. Urban Syst. 2007, 31, 667-688. [CrossRef]

36. Cabral, P.; Zamyatin, A. Markov Processes in Modeling Land Use and Land Cover Changes in Sintra-Cascais, Portugal. Dyna 2009, 191-198.

37. Liu, Y. Modelling Urban Development with Geographical Information Systems and Cellular Automata; Taylor \& Francis Group: New York, NY, USA, 2009; p. 177.

38. Lepš, J. Mathematical modelling of ecological succesion-A review. Folia Geobot. Phytotax. 1988, $23,79-94$. [CrossRef]

39. Arsanjani, J.J.; Kainz, W.; Mousivand, A.J. Tracking dynamic land-use change using spatially explicit Markov Chain based on cellular automata: The case of Tehran. Int. J. Image Data Fusion 2011, 2, 329-345. [CrossRef]

40. Camacho, O.M.T.; Pontius, R.G., Jr.; Paegelow, M.; Mas, J.F. Comparison of simulation models in terms of quantity and allocation of land chance. Environ. Model. Softw. 2015, 69, 214-221. [CrossRef]

41. Yang, X.; Zheng, X.-Q.; Lv, L.N. A spatiotemporal model of land use change based on ant colony optimization, Markov chain and cellular automata. Ecol. Model. 2012, 233, 11-19. [CrossRef]

42. INEGI (Instituto Nacional de Estadística, Geografía e Informática) 2012-Información Nacional, por Entidad Federativa y Municipios. Available online: www.inegi.org.mx/ (accessed on 24 February 2016). (in Spanish).

43. Richards, J.A.; Jia, X. Remote Sensing Digital Image Analysis: An Introduction, 4th ed.; Springer-Verlag: Berlin, Germany, 2006; p. 439.

44. Eastman, J.R.; Van Fossen, M.E.; Solarzano, L.A. Transition Potential Modeling for Land Cover Change. In GIS, Analysis, Spatial, Modeling; Maguire, D.J., Goodchild, M.F., Batty, M., Eds.; ESRI Press: Redlands, CA, USA, 2005; p. 386.

45. Mitsova, D.; Shuster, W.; Wang, X. A cellular automata model of land cover change to integrate urban growth with open space conservation. Landsc. Urban Plan. 2011, 99, 141-153. [CrossRef]

46. Bhattacharyya, A. On a measure of divergence between two statistical populations defined by their probability distributions. Bull. Calcutta Math. Soc. 1943, 35, 99-109.

47. Eastman, R.; Idrisi, T. Guide to GIS and Image Processing, Manual Version 16.02; Clark University: Worcester, MA, USA, 2009; p. 342.

48. Smits, P.C.; Dellepiane, S.G.; Schowengerdt, R.A. Quality assessment of image classification algorithms for land-cover mapping: A review and a proposal for a cost-based approach. Int. J. Remote Sens. 1999, 20, 1461-1486. [CrossRef]

49. Congalton, R.G.; Oderwald, R.G.; Mead, R.A. Assessing Landsat classification accuracy using discrete multivariate analysis statistical techniques. Photogramm. Eng. Remote Sens. 1983, 49, 1671-1678.

50. Mousivand, A.J.; Alimohammadi, S.A.; Shayan, S. A New Approach of Predicting Land Use and Land Cover Changes by Satellite Imagery and Markov chain model (Case study: Tehran). Ph.D. Thesis, Tarbiat Modares University, Tehran, Iran, 2007.

51. Benenson, I.; Torrens, P.M. Geosimulation: Automata-Based Modeling of Urban Phenomena; Wiley: Chichester, UK, 2004; pp. 1-287.

52. Strigul, N.; Florescu, I.; Welden, R.A.; Michalczewski, F. Modelling of forest stand dynamics using Markov chains. Environ. Model. Softw. 2012, 31, 64-65. [CrossRef] 
53. Clark Labs. IDRISI Geographic Information Systems and Remote Sensing Software; Clark Labs: Worcester, MA, USA, 2006.

54. Wolfram, S. Cellular automata as models of complexity. Nature 1984, 311, 419-424. [CrossRef]

55. Vazquez, Q.G.; Pinedo, A.A.; Manjarrez, D.C.; De Leon, M.G.; Hernandez, R.A. Analysis of temperate forest fragmentation using spatial medium-resolution remote sensing in Pueblo Nuevo, Durango. Tecnociencia Chihuahua 2013, 7, 88-98.

56. Renteria, A.B.; Treviño, G.E.; Navar, C.J.; Aguirre, C.O.; Silva, C.I. Woody fuel assessment in the ejido Pueblo Nuevo, Durango. Rev. Chapingo 2005, 11, 51-56.

57. Pompa, G.M.; Zapata, M.M.; Hernandez, D.C.; Rodriguez, T.E. Geospatial model as strategy to prevent forest fires: A case study. J. Environ. Prot. 2012, 3, 1034-1038. [CrossRef]

58. FAO. Food and Agriculture Organization. State of the World's Forest. Available online: http://www.fao.org/ docrep/016/i3010e/i3010e.pdf (accessed on 24 February 2016 2016).

(C) 2016 by the authors; licensee MDPI, Basel, Switzerland. This article is an open access article distributed under the terms and conditions of the Creative Commons by Attribution (CC-BY) license (http://creativecommons.org/licenses/by/4.0/). 